\title{
Redes de sociabilidade, autocultuação e tradições: as práticas intelectuais do Instituto Histórico e Geográfico Brasileiro (1964- 1985)*
}

\author{
Sociability networks, self-cultivation and traditions: the intellectual practices of the \\ Brazilian Historical and Geographic Institute (1964-1985)
}

Fernanda Coelho Mendes

Doutoranda do Programa de Pós-Graduação em História Social da UFRJ

fmendes91@hotmail.com

\begin{abstract}
Resumo: Como instituição intelectual, o IHGB conta ao longo de sua história já quase bicentenária com muitos rituais, tradições e redes de sociabilidade que alimentam o seu ano social e produzem material para a publicação de sua Revista. Utilizando como recorte temporal à vigência da ditadura civilmilitar no país, de 1964 a 1985, este artigo se propõe a analisar as práticas intelectuais do Instituto durante este período, os rituais e tradições que compunham sua rotina, a interação entre os sócios e a interseção com outras instituições intelectuais, identificando um ponto em comum entre todas essas práticas: o culto de si. Para isso, serão utilizados como fontes os discursos, artigos, relatórios e demais documentos publicados na Revista do IHGB durante este período.
\end{abstract}

Palavras Chaves: IHGB; práticas intelectuais; redes de sociabilidade.

\begin{abstract}
As an intellectual institution, the IHGB has in its almost bicentennial history many rituals, traditions and sociability networks that feed its social year and produce material for the publication of its magazine. Using as a time framework the civil-military dictatorship in the country, from 1964 to 1985, this article aims to analyze the intellectual practices of the Institute during this period, the rituals and traditions that composed its routine, the interaction between the members and the intersection with other intellectual institutions, identifying a commonality between all these practices: the self-worship. In order to do this, the speeches, articles, reports and other documents published in the IHGB' Revista during this period will be used as sources.
\end{abstract}

Keywords: IHGB; intellectual practices; sociability networks.

\footnotetext{
* Pesquisa financiada pela CAPES.
} 


\section{A dinâmica interna do IHGB}

O Instituto Histórico e Geográfico Brasileiro (IHGB) é uma das mais antigas instituições culturais da América Latina, fundado em 1838 por um grupo de políticos e intelectuais residentes na Corte. De lá para cá, o Instituto mudou algumas vezes de sede, passou por fases de maior e menos prestígio e prosperidade, mas seguiu acompanhando de perto os rumos políticos e sociais do país.

A parceria entre o IHGB e o Estado foi, desde a sua fundação, fator importante e definidor para o perfil desta instituição. Durante o Brasil Império, conforme destaca Lucia Paschoal Guimarães (1995), o IHGB se aliou ao poder público e, "sob os auspícios" de D. Pedro II, desempenhou papel importante na construção da memória e da identidade nacional, colaborando, desta forma, para a consolidação do Estado Imperial.

Engajado em um projeto de construção da nação brasileira, o IHGB atuou selecionando, arquivando e publicando documentos e trabalhos para a escrita de uma História do Brasil “oficial”, contribuindo assim para a consolidação do Estado Nacional brasileiro. Segundo Manoel Luís Salgado Guimarães (1988), o Instituto produzia uma historiografia apoiada em noções de progresso e desenvolvimento, organizadas de forma linear e pragmática, a qual colaborou para a definição das ideias de nação e nacionalidade baseadas em uma noção de "tarefa civilizatória" herdada da colonização portuguesa no país.

Embora tenha vivido seus anos dourados durante o Império e sofrido uma queda significativa de prestígio e de patrocínio estatal com o fim da Monarquia no país, o IHGB seguiu se reinventando e se adequando às novas formas de sistemas políticos, ainda que se aproximasse mais ou menos de determinados governos. A instituição, criada na primeira metade do século XIX, atravessou todo o século XX e continua funcionando atualmente, encaminhando-se para a comemoração do seu bicentenário.

Para este artigo, optou-se por analisar o IHGB sob o recorte temporal correspondente à vigência da ditadura civil-militar, de março de 1964 a março de 1985, uma vez que os resultados aqui apresentados fazem parte de uma pesquisa maior, ainda em andamento, a qual engloba as relações entre os intelectuais do IHGB e os governos militares. 
A partir de 1965, com a reforma dos seus estatutos, o IHGB passou a ser composto por cinco sócios grandes beneméritos, 15 sócios beneméritos, 50 sócios efetivos, 50 sócios correspondentes, sendo 10 portugueses, e 40 sócios honorários, somando um total de 165 intelectuais. Sempre que um deles falecia, a vaga em aberto era preenchida pela eleição de um novo sócio. Considerando o recorte temporal desta pesquisa, identificamos 273 sócios brasileiros ou naturalizados brasileiros que passaram pelo IHGB durante o período pesquisado. Deste total, 121 já faziam parte do Instituto quando o golpe aconteceu, em 1964. Os 152 restantes foram eleitos já sob a vigência da ditadura.

O Instituto possuía uma administração composta pelo presidente, por três vicepresidentes $\left(1^{\circ}, 2^{\circ}\right.$ e $\left.3^{\circ}\right)$, por dois secretários $\left(1^{\circ}\right.$ e $\left.2^{\circ}\right)$, por um orador e um tesoureiro. Além disso, existiam ainda sete comissões permanentes: Fundos e Orçamento; Estatutos; História; Geografia; Etnografia e Arqueologia; Bibliografia; e Admissão de Sócios. Os mandatos tanto da diretoria quanto das comissões eram bienais, sendo permitida a reeleição. (RIHGB, jan./mar. 1965: 293) Havia, ainda, o cargo de editor da revista do Instituto, ocupado através da indicação do presidente.

Em janeiro de 1967 foi criada também a Comissão de Estudos e Pesquisas Históricas, a CEPHAS, com o objetivo de elaborar programas de atividades voltadas para a área, como congressos, cursos e conferências. (RIHGB, jan./mar. 1967: 244) Todos os sócios do IHGB automaticamente faziam parte da CEPHAS, que tinha ainda um presidente, indicado diretamente pelo presidente do Instituto e sem um período prédeterminado para o seu mandato.

Em 1964, quando tem início nossa análise sobre o IHGB, o presidente era José Carlos de Macedo Soares, o $1^{\text {o }}$ vice-presidente era Rodrigo Octávio Filho, o $2^{\circ}$ vicepresidente era José Wanderley Araújo Pinho e o $3^{\circ}$, Henrique Carneiro Leão Teixeira Filho. Conforme avançaram os anos, esses intelectuais faleceram e abriram espaço para uma nova diretoria. Já em 1968, o presidente do Instituo passou a ser Pedro Calmon; no ano seguinte, Américo Jacobina Lacombe se tornou $1^{\circ}$ vice-presidente; Arthur Cezar Ferreira Reis assumiu o cargo de $2^{\circ}$ vice-presidente e Virgílio Corrêa Filho, o de $3^{\circ}$, formação que foi mantida até 1985, com exceção de Virgílio, que faleceu em 1973 e foi substituído por Antônio Camillo de Oliveira até 1982 e depois por Jonas de Morais Filho.

A rotina do IHGB era composta por sessões ordinárias, extraordinárias e magnas, além de eventuais assembleias gerais e congressos ou seminários organizados 
para abordar temas especiais. As sessões ordinárias eram realizadas mensalmente, de abril até outubro, e tinham como objetivo realizar debates acadêmicos e exposições de trabalhos nas áreas contempladas pelo IHGB. As sessões extraordinárias e assembleias gerais eram convocadas pelo presidente ou por pelo menos 25 sócios e tratavam de assuntos específicos, como eleição da diretoria, reforma do estatuto ou entrega de prêmios. A sessão magna, por sua vez, era realizada sempre no dia 21 de outubro de cada ano para celebrar o aniversário da instituição.

Além dos encontros presenciais que compunham o ano social, o Instituto tinha como importante parte da sua dinâmica interna a produção da sua Revista. A RIHGB possuía - e ainda possui - quatro edições ao ano: de janeiro a março; de abril a junho; de julho a setembro; e de outubro a dezembro, resultando em uma publicação do tipo trimestral. O objetivo do periódico era divulgar as atividades desenvolvidas pelos sócios no ano social do Instituto, incluindo trabalhos acadêmicos, discursos proferidos, artigos, conferências e cursos realizados, relatórios, entre outros. O número de páginas era bastante variável, dependendo da quantidade de trabalhos reunidos, os quais muitas vezes traziam mapas, gravuras, reproduções de cartas ou outros tipos de imagens. Geralmente as edições traziam no mínimo 200 páginas, mas eventualmente o número poderia passar de 400, a depender do tamanho do conteúdo.

Para pensarmos sobre as formas de interação entre os intelectuais do IHGB, nos baseamos no conceito de redes de sociabilidade, proposto por Jean-François Sirinelli (1996). Segundo o historiador, o meio intelectual se constitui em um "pequeno mundo estreito", organizado em torno de sensibilidades ideológicas ou culturais em comum, as quais forjam relações de amizade, fidelidade, influências e ainda de conflitos e exclusões entre os intelectuais que o integram.

Neste sentido, pretende-se analisar o "pequeno mundo estreito" do IHGB, as sensibilidades ideológicas e/ou culturais que ali permeavam, as redes de sociabilidade desenvolvidas entre seus membros e com outras instituições intelectuais, os debates suscitados e as relações de afinidade - ou de conflitos - advindas. Para isso, a Revista do Instituto aparece como lugar privilegiado para se pensar as redes ali construídas. Conforme destaca Sirinelli, "uma revista é antes de tudo um lugar de fermentação intelectual e de relação afetiva, ao mesmo tempo viveiro e espaço de sociabilidade". (1996: 249) 


\section{As relações estreitas com a ABL e o CFC}

Ao fazer o exercício de mapear as principais redes nas quais os sócios do IHGB estavam inseridos na segunda metade do século XX, outras duas instituições intelectuais se destacam pela significativa interseção de membros com o Instituto: a Academia Brasileira de Letras (ABL) e o Conselho Federal de Cultura (CFC).

Usando como recorte temporal o período de 1964 a 1985, identificamos 20 sócios do Instituto que também faziam parte da ABL: Afonso Pena Júnior, Alexandre Barbosa Lima Sobrinho, Américo Jacobina Lacombe, Aníbal Freire da Fonseca, Antônio Carneiro Leão, Arnaldo Niskier, Aurélio de Lyra Tavares, Cândido Motta Filho, Elmano Cardim, Evaristo de Moraes Filho, Ivan Lins, José Carlos de Macedo Soares, José Honório Rodrigues, Levi Carneiro, Luís Vianna Filho, Múcio Leão, Odylo Costa, Filho, Raimundo Magalhães Júnior, Rodrigo Octávio Filho e Sérgio Correa da Costa.

O Conselho Federal de Cultura, criado em novembro de 1966 pelo governo Castello Branco, reuniu pelo menos doze sócios do $\mathrm{IHGB}^{1}$ : Arthur Cezar Ferreira Reis, Clarival do Padro Valadares, Djacir Lima Menezes, Gilberto Freyre, Hélio Vianna, Manuel Diegues Júnior, Moyses Vellinho, Plínio Doyle, Raymundo Moniz de Aragão, Renato Soeiro, Rodrigo de Mello Franco de Andrade e Silvio Meira.

Além desses 32 intelectuais citados, temos ainda seis sócios que atuaram nas três instituições culturais durante o período pesquisado: Afonso Arinos de Mello Franco, Clodomir Vianna Moog, Francisco de Assis Barbosa, Josué Montello, Miguel Reale e Pedro Calmon. Temos, portanto, um total de 35 intelectuais no IHGB frequentando também o Conselho Federal de Cultura, a Academia Brasileira de Letras ou ambas.

Maria Diégues Quintella (1984) analisou a atuação destas três instituições intelectuais na década de 1970 e observou uma série de características em comum entre elas: o seu caráter tradicional, atuando em função da preservação cultural; a formação polimorfa ou polivalente de seus membros, permitindo-lhes discursar sobre temas variados; a ocupação de importantes cargos públicos, não sendo rara também a atuação

\footnotetext{
${ }^{1}$ Não foi encontrado um trabalho acadêmico que listasse todos os intelectuais que passaram pelo Conselho de 1966 até 1991, quando o mesmo deixou de existir. Por conta disso, utilizamos como fonte a pesquisa de Tatyana de Amaral Maia, que abrange o período de 1966 a 1975, fazendo a ressalva de que a quantidade de intelectuais que atuou tanto no IHGB quanto no CFC pode ser maior do que a mencionada aqui. Cf. MAIA, Tatyana de Amaral (2012). Os cardeais da política nacional: o Conselho Federal de Cultura na ditadura civil-militar (1967-1975). São Paulo: Itaú Cultural: Iluminuras.
} 
política; a participação ampla em outras instituições, tanto nacionais quanto internacionais; o tratamento cordial entre os pares; a autocultuação como forma de legitimação; e a recorrência dos atores envolvidos na ABL, no CFC e no IHGB, revezando e acumulando lugares de prestígio nas principais instituições culturais brasileiras e construindo assim uma certa homogeneidade.

Segundo a autora, essa tríade intelectual é formada por instituições que "voltamse para si mesmas", atuando de modo introspectivo entre seus próprios membros a partir de encontros e reuniões periódicas. Neste sentido, são instituições “idealizadas e criadas com o propósito de legitimar, através da institucionalização, a posição de determinadas pessoas frente à comunidade onde elas surgiram" (QUINTELLA, 1984: 116), diferentemente de instituições criadas há menos tempo, que seriam mais voltadas para o exterior e preocupadas em conciliar seus interesses com os da sociedade em geral.

Uma das principais características desta tríade é, portanto, a inexistência de conflitos significativos entre elas, que pudessem por em risco a homogeneidade do grupo e sua posição como elite, justamente a partir da repetição dos mesmos membros em posições de poder nas diferentes instituições.

Não temos, no caso em questão, um grupo formado a partir do Conselho Federal de Cultura, outro da Academia Brasileira de Letras e outro do Instituto Histórico e Geográfico Brasileiro que estabelecessem entre si algum tipo de competição. O que encontramos de fato é um mesmo grupo que, com pequenas diferenças de acordo com a especificidade da instituição, se repete, se faz presente e se perpetua nas três instituições analisadas. (QUINTELLA, 1984: 116)

Inspirada na Academia Francesa de Letras, a ABL foi criada em 1897, com sede no Rio de Janeiro, e teve como fundador e primeiro presidente o intelectual Machado de Assis. A instituição é composta por 40 membros permanentes e 20 sócios correspondentes estrangeiros, eleitos pelos próprios acadêmicos.

Durante o período pesquisado, era comum a visita de imortais ao IHGB, incluindo o presidente da Academia Austregésilo de Athayde, principalmente em ocasiões solenes como a celebração do aniversário do Instituto ou conferências de homenagem ao aniversário de nascimento ou morte de um intelectual. Para a realização da sessão magna de 1974, por exemplo, compareceram Austregésilo de Athayde e 
Raimundo Moniz de Aragão, presidente do CFC à época. Durante a sessão magna, Athayde homenageou o IHGB oferecendo-lhe a medalha Machado de Assis e um exemplar de primeira edição da obra Os Lusíadas. Em retribuição, Pedro Calmon ofereceu à ABL a medalha de prata do sesquicentenário da Independência do Brasil. (RIHGB, out./dez. 1975: 185-186)

O Conselho Federal de Cultura foi a instituição intelectual com relações mais próximas desenvolvidas com o IHGB durante o período pesquisado. O CFC foi criado em 21 de novembro de 1966 pelo Decreto-Lei n 74, mas começou a funcionar de fato apenas em fevereiro do ano seguinte, e teve a sua dissolução decretada em 1990. O Conselho foi inicialmente composto por 24 intelectuais, nomeados diretamente pelo então presidente da República, o marechal Castello Branco, e elegeu Josué Montello e Pedro Calmon, respectivamente, presidente e vice-presidente do órgão - ambos membros do IHGB na época em que o Conselho foi criado.

Segundo Lia Calabre (2006), o CFC tinha caráter normativo e de assessoramento ao Ministério da Educação e Cultura (MEC). Assim, os pareceres votados pelo órgão serviam como recomendações a serem executadas pelo ministério. O Conselho recebia um determinado orçamento para financiar ações e projetos próprios e para conceder auxílio financeiro a instituições e outros projetos culturais que julgasse pertinentes auxílio do qual o IHGB obteve benefícios significativos.

A relação entre o IHGB e o CFC foi próspera e contou com muitas parcerias entre ambas as instituições ao longo dos anos. Os dois primeiros presidentes do Conselho eram membros do Instituto: Josué Montello (1967-1968) e Arthur Cezar Ferreira Reis (1969-1972). Durante o período em que presidiu o CFC, Ferreira Reis acumulou ainda o cargo de $2^{\circ}$ vice-presidente do IHGB, o qual ocupou de 1969 até 1985 .

Durante boa parte do período pesquisado, o Conselho fazia um repasse anual de auxílio financeiro para o IHGB, destinado à "manutenção dos seus serviços habituais". (RIHGB, out./dez. 1969: 208) Além disso, o CFC também financiava empreendimentos específicos, como auxílio para a publicação de livros escritos pelos sócios, a microfilmagem de documentos do seu arquivo, a realização de cursos e eventos acadêmicos, além da construção da nova sede do Instituto, inaugurada em 1972, na qual o Conselho teve papel primordial fazendo os repasses de financiamento que eram aprovados pelo governo militar. 
A relação entre as instituições era tão relevante que aparecia quase sempre como um tópico dentro do relatório anual sobre as atividades culturais do Instituto, geralmente intitulado "O IHGB e o Conselho Federal de Cultura". Neste tópico o secretário prestava as contas dos repasses recebidos e informava aos demais sócios sobre as parceiras e convênios firmados. Era comum o texto se iniciar relatando as relações entre as duas instituições como as "melhores", "mais gratas" e "mais amistosas" possíveis, seguido de agradecimentos feitos ao CFC pelos auxílios concedidos.

Em diversos momentos, ainda, o próprio IHGB evidenciou a repetição de membros entre ambas as instituições como um fator favorável ao Instituto. No relatório anual de 1980, Xavier Pedrosa destaca que "continua de pé o convênio entre as duas instituições culturais que contam nos respectivos quadros sociais com membros pertencentes as duas, o que a nosso ver facilita anualmente a sua renovação". (RIHGB, out./dez. 1980: 169)

Uma vez estabelecida a dinâmica interna do IHGB e a importância de sua rede de sociabilidade, veremos a seguir as particularidades do ambiente intelectual existente no Instituto, investigando seus rituais, tradições e práticas intelectuais, de modo a compreender suas características próprias enquanto instituição cultural.

\section{O culto de si}

O IHGB possuía diversas práticas intelectuais específicas do seu cotidiano e, por vezes, em comum com outras instituições culturais. Conferências, homenagens, relatórios de atividades, debates, artigos, discursos de recepção a novos membros, eleições de presidentes de honra, elogios aos sócios falecidos... os tipos de eventos eram muitos, e, embora cada um guardasse as particularidades de seus formatos, todos eles trazem uma importante característica em comum: o autoelogio, direcionado tanto ao IHGB quanto aos próprios sócios que o integravam.

O conteúdo da Revista, composto principalmente por transcrições de cursos, conferências e demais discursos proferidos no ano social do Instituto, traz a todo o momento elogios à Casa e aos seus pares feitos por eles mesmos, consistindo em uma prática de culto de si, ou, como denomina Maria Diégues Quintella, “autocultuação”.

Segundo a autora, a autocultuação pode ser feita de modo direto, onde membros de uma instituição elogiam seus próprios colegas, ou de forma indireta, quando os 
elogios são destinados a um indivíduo que não pertence àquela determinada instituição, podendo estar vivo ou morto, mas devendo estar reconhecidamente no mesmo nível de prestígio. Neste segundo caso, a autocultuação assumiria a forma de "projeção", ou seja, "são projetadas nestes indivíduos as qualidades ou características requisitadas para o próprio grupo”. (QUINTELLA, 1984: 132) Quintella destaca ainda a importância de haver sempre um tempo destinado ao debate e à exposição acadêmica de temas culturais, o que fornece o espaço necessário para que os membros da instituição possam de uma só vez reforçar suas características enquanto intelectuais pertencentes a uma elite cultural e demonstrar seu domínio sobre conhecimentos específicos.

Como veremos ao longo deste artigo, identificamos como formas de autocultuação o elogio entre os pares e o uso dos espaços do Instituto para a demonstração de conhecimentos acadêmicos específicos, presentes nas saudações aos novos sócios, nos discursos de ingresso no IHGB e nas homenagens aos sócios falecidos. Além desses espaços de fala, também era prática frequente a organização de conferências para homenagear determinado aniversário de nascimento ou de morte de algum sócio importante na história do Instituto, ou mesmo para homenagear o tempo de casa completado por um intelectual.

Em 1980, por exemplo, o IHGB promoveu a comemoração do bicentenário de nascimento do cônego Januário da Cunha Barbosa, um dos seus fundadores e primeiro secretário perpétuo. Para homenageá-lo, organizou-se uma exposição com retratos e documentos referentes à trajetória de Januário, uma série de conferências feita pelos sócios sobre aspectos da sua vida e ainda a publicação de artigos na Revista sobre o tema. (RIHGB, jan./mar. 1981: 261-263)

Em agosto do ano seguinte, o Instituto organizou uma homenagem pelo cinquentenário da eleição dos sócios Pedro Calmon e Barbosa Lima Sobrinho. A sessão especial teve início com longo discurso de Dalmo Freire Barreto, encarregado de relembrar e ressaltar as trajetórias de vida dos intelectuais homenageados, suas atuações intelectuais e profissionais e os traços mais marcantes de suas personalidades, sempre de forma extremamente elogiosa e reverente. Em seguida, passou-se a palavra a Barbosa Lima Sobrinho e depois a Pedro Calmon, para que pudessem agradecer às homenagens prestadas e demonstrar toda sua gratidão ao Instituto que os acolhia há 50 anos. (RIHGB, out./dez. 1981: 71-92)

Contudo, era o ritual de ingresso dos novos sócios a forma mais frequente de altocultuação "direta", quando membros de uma mesma instituição trocavam elogios. 
As eleições para novos membros aconteciam para preencher a vaga aberta com o falecimento de algum intelectual. Uma vez eleito o novo sócio, marcava-se a cerimônia de posse, geralmente realizada em sessão ordinária no IHGB, ocasião em que o empossado era recepcionado por um discurso realizado por um dos sócios, apresentando-se sua biografia, sua carreira profissional e suas principais obras publicadas. Em seguida, o novo membro proferia um discurso acadêmico sobre uma temática de livre escolha, relacionada a sua área de estudos. ${ }^{2}$

Era comum os candidatos saírem de comissões, simpósios ou cursos de variados temas organizados pelo Instituto com ajuda externa, ou ainda, palestrantes convidados a participar de eventos realizados em suas dependências que agradavam os demais sócios e eram lembrados quando uma nova vaga se abria. Após a criação da CEPHAS, em 1967, normalmente o novo pleiteante começava primeiro a frequentar essas reuniões, criando suas redes de sociabilidade entre os intelectuais do IHGB, para depois ser indicado a uma vaga de sócio efetivo.

Assim, raramente era eleito um candidato que não tivesse nenhuma relação profissional e principalmente de amizade com pelo menos alguns dos sócios. Para fazer o discurso de recepção, era habitual que o ingressante solicitasse um intelectual com quem já tivesse proximidade. Quando isso não acontecia, era o presidente do IHGB quem designava alguém para fazê-lo.

Os discursos de recepção geralmente seguiam um padrão semelhante. Chamados de "saudação ao sócio", os intelectuais sempre pontuavam suas falas com diversos elogios ao novo companheiro, destacando seus feitos, suas obras e características de sua personalidade. Outra prática frequente era relembrar como havia conhecido o candidato eleito, aonde trabalharam juntos, se fosse o caso, e como foi construída a relação de amizade entre ambos. As saudações costumavam apresentar de forma detalhada a biografia do ingressante, contando aonde nasceu, à qual família pertencia, aonde estudou e atuou profissionalmente, além de expor de forma detalhada a bibliografia de sua autoria.

Era comum os sócios responsáveis pelas saudações se dedicarem às obras publicadas pelos candidatos eleitos, fazendo exposições bastante detalhadas, contextualizando e discutindo o teor desses trabalhos em seus discursos de recepção. Ou seja, as saudações aos ingressantes se tornavam, além de uma oportunidade para

\footnotetext{
2 Antes disso, era exigido que o novo sócio entregasse uma cópia de seu discurso ao presidente do Instituto, com antecedência de pelo menos oito dias, para ser aprovado pela diretoria.
} 
reforçar os laços de amizade e as redes de sociabilidade daqueles intelectuais, uma possibilidade de demonstrar conhecimento acadêmico perante os seus demais confrades.

O sócio Paulo Ferreira Santos recebeu, em julho de 1977, o ingressante Lucas Mayerhofer, com quem tinha uma relação profissional e de amizade, iniciada quando ambos foram alunos da Escola Nacional de Belas Artes. Ferreira Santos escolheu o tema "duas vidas paralelas" para fazer a sua saudação, traçando justamente um paralelo detalhado entre as vidas de ambos os sócios, mostrando os pontos de aproximação e afastamento entre eles.

Nossas diferenças de temperamento e de gosto começaram na escolha dos caminhos, que só no ocaso da vida estamos podendo perceber quais foram. Se em vós predominou o da Beleza, se expressando na Arte, e mais caracterizadamente na História da Arte, em mim os três caminhos se fundiram num só, em busca de um equilíbrio que costumais dizer ser uma das minhas constantes [...]. Nossos gostos não diferiam apenas nos autores a que nos apegávamos, mas, num mesmo autor, de livro para livro. Em Goethe, por exemplo, atraiu-me o pré-romantismo rousseauniano, quase doentio, do Werther, que tantos suicídios ocasionou; e em vós, o Fausto. (RIHGB, out./dez. 1977: 41-45)

Além de apresentar e recepcionar o novo sócio, Ferreira Santos utiliza o espaço de sua saudação para falar também de si, apresentando sua formação acadêmica, sua relação com a arte e com autores renomados. Assim, o intelectual segue, ao longo de todo o discurso, evidenciando seu domínio sobre diferentes áreas do conhecimento, na arquitetura, na filosofia, na educação, nas artes, entre outras. Essa era uma prática comum nas saudações aos novos sócios. Embora nem todos falassem tão diretamente sobre si, como Ferreira Santos e sua temática das vidas paralelas, muitos demonstravam conhecimento fazendo citações em latim ou francês, debatendo temas referentes à área de atuação do sócio ingressante, discutindo em detalhes suas obras principais.

Maria Quintella aponta justamente como um das características deste grupo a consciência dos intelectuais sobre o seu papel como produtores de cultura, o que inclui qualquer iniciativa tomada neste campo, podendo ter sido produzida tanto dentro quanto fora das instituições culturais. Os próprios intelectuais se encarregavam de comentar e apresentar aos demais as produções feitas por membros do próprio grupo, na maior 
parte das vezes referindo-se a elas e a seus autores, seus pares, com adjetivos positivos e elogiosos. (QUINTELLA, 1984: 130)

Esta prática era frequente no IHGB e aparece em sessões ordinárias e reuniões das CEPHAS. Contudo, esta "consciência de produtor de cultura" também está presente, como foi brevemente mostrado, nos discursos de recepção aos novos sócios. A demonstração de conhecimento sobre a obra publicada pelo ingressante era item praticamente obrigatório nessas saudações e incluía a apresentação dos trabalhos mais importantes, feita sempre de forma elogiosa, e por vezes uma discussão mais aprofundada sobre o conteúdo, momento em que o sócio tinha a chance de exercer plenamente seu papel de produtor de cultura.

Uma vez feito o discurso de saudação, a palavra era passada ao novo sócio, que deveria fazer uma exposição acadêmica sobre algum assunto que dominasse. Antes de dar início a sua apresentação, contudo, era comum que o ingressante tecesse elogios ao intelectual que o recebera e ao IHGB, valorizando a instituição para a qual era eleito e os sócios que a integravam.

Em 1966, na cerimônia de posse de Lourenço Luiz Lacombe, à época presidente do Instituto Histórico de Petrópolis (IHP), o intelectual faz uma descrição de seus nobres sentimentos ao ser eleito para o IHGB:

A emoção que embarga a voz não é mera figura de retórica a emoldurar um discurso. É um fato perfeitamente justificável e, de resto, facilmente comprovável. Aqui me encontro, minha Senhoras e meu Senhores emocionado por ocupar esta tribuna, que, se por um lado, me envaidece e exalta, por outro, intimida e constrange o pobre cultor da História da velha província, que vem tomar assento entre os historiadores que compõem o colendo Instituto Histórico e Geográfico Brasileiro. E minha emoção aumenta ao pousar os olhos nestas bancadas, ocupadas por queridos e velhos amigos, alguns dos quais já eram, de longa data, meus confrades (com grande honra para mim) no Instituto Histórico de Petrópolis. (RIHGB, jul./set. 1966: 265)

O discurso de Lacombe expõe não apenas a reverência emocionada dedicada ao IHGB, mas também a existência de outras redes de sociabilidade que circulavam ao redor do Instituto e acabavam ajudando a compô-lo, como é o caso do Instituto Histórico de Petrópolis (IHP). Muitos sócios integraram as duas instituições 
intelectuais, como Henrique Carneiro Leão Teixeira Filho, Wanderley de Araújo Pinho, Américo Jacobina Lacombe, Arthur Cezar Ferreira Reis, Hélio Vianna e, a partir de 1966, Lourenço Luiz Lacombe, que presidia o IHP e tornou-se sócio assíduo do IHGB quando eleito, fazendo parte da Comissão de Admissão de Sócios de 1980 a 1985.

O convívio em instituições culturais paralelas, assim como em redações de periódicos, em cargos públicos ou em universidades, contribuía diretamente para a eleição de novos sócios no IHGB. O inverso também acontecia: o convívio no Instituto favorecia a entrada desses intelectuais em outras instituições de prestígio, como a ABL ou o Conselho Federal de Cultura, por exemplo. E os processos de troca e construção destas redes de sociabilidade mais ou menos restritas, onde quase todos se conheciam e conviviam nos mesmos ambientes, consequentemente contribuíam para a manutenção deste grupo no poder.

O advogado e bibliófilo Plínio Doyle foi eleito em 1969 e empossado no ano seguinte, recebido por Haroldo Teixeira Valladão, orador oficial do IHGB de 1971 a 1985. Seu discurso de posse evidencia também o rito de elogios à Casa que o recebia e a existência de uma rede de sociabilidades no qual o Instituto se inseria:

O ingresso nesta casa centenária não estava nas minhas cogitações. Os poucos trabalhos meus não me davam esperança de boa acolhida. Eis senão quando os amigos aqui me trouxeram. Impossível recusar. Aceitar era a única solução, sabendo de antemão que as responsabilidades eram muitas e poucas as minhas forças. E ser membro do Instituto Histórico e Geográfico Brasileiro era a glória que chegava para mim, que ficava em meu coração, elevando o meu nome, honrando as minhas tradições e consolando-me das lutas e canseiras, por ver reconhecidos os poucos préstimos de minhas pesquisas. Essa a glória que fica, eleva e consola. (RIHGB, abr./jun. 1971: 162)

Plínio Doyle comenta, em sua cerimônia de posse, que seus amigos foram os responsáveis por trazê-lo ao Instituto, convite considerado "impossível recusar". De fato, eram muitas as redes de sociabilidade de Doyle que se cruzavam com os sócios do IHGB. Na década de 1920, ingressou no curso de Direito da Faculdade de Ciências Jurídicas e Sociais do Rio de Janeiro, onde participou do Centro Acadêmico Jurídico 
Utilitário $^{3}$ (Caju) ao lado de nomes como Américo Jacobina Lacombe, Hélio Vianna, Thiers Martins Moreira - todos os três já integrantes do IHGB no ano da eleição de Doyle. (RANGEL, 2008)

Após concluir o curso superior, Plínio passou a trabalhar no escritório de advocacia de Haroldo Valladão, seu professor na universidade e, anos mais tarde, o sócio que o receberia com discurso de saudação no IHGB. A partir de 1935, passou a advogar para a editora José Olympio e, paralelamente, foi intensificando a aquisição de livros, jornais e revistas, resultando na formação de uma biblioteca com 25 mil volumes. (RANGEL, 2008)

Sua extensa biblioteca, acomodada em seu apartamento em Ipanema, lhe rendeu a organização de um encontro semanal que ficaria conhecido como "Sabadoyle"4. O evento teve início oficialmente na véspera do natal de 1964, quando passou a receber nas tardes de sábado o amigo Carlos Drummond de Andrade, com quem convivia nos tempos de José Olympio, para trabalhar na elaboração de índices de artigos das revistas que colecionava. Américo Jacobina Lacombe, na época presidente da Fundação Casa de Rui Barbosa e amigo próximo de Doyle desde os tempos de estudantes de Direito, foi ao encontro dos intelectuais para que Drummond fizesse a apresentação de um livro seu. A partir daí, a notícia das reuniões aos sábados se espalharam e cada vez mais intelectuais passaram a frequentar semanalmente a casa de Doyle, tanto para ter acesso a sua rica biblioteca quanto para participar dos eventos sociais, que consistiam em encontros informais sobre diversos assuntos, como o lançamento de livros, resenhas, datas comemorativas, críticas literárias, homenagens, entre outros. (RANGEL, 2008)

Além de Américo Jacobina Lacombe, um dos "fundadores" do Sabadoyle, muitos sócios do IHGB frequentaram as reuniões de Plínio, como Afonso Arinos, Luís Vianna Filho, Eduardo Canabrava Barreiros, Cândido Motta Filho - todos esses já membros do Instituto quando Plínio foi eleito. É interessante notar, ainda, o número expressivo de intelectuais que passaram pelo Sabadoyle e ingressaram no IHGB após a eleição de seu anfitrião: Fernando Monteiro (eleito em 1971), Raul Lima (1971), Nelson Lavenère-Wanderley (1972), Horácio de Almeida (1975), Monsenhor Guilherme Schubert (1975), Donato Mello Júnior (1976), Silvio Meira (1980), Álvaro Cotrim (1981).

\footnotetext{
${ }^{3} \mathrm{O}$ Caju tinha como objetivo reunir os alunos em grupos de estudos para debater e estudar as disciplinas do curso. Mais tarde teve seu nome alterado para Centro de Estudos Jurídicos e Sociais.

${ }^{4}$ O apelido para os encontros foi dado por Raul Bopp em 1974, entendendo-se até 1998, quando foram encerrados por conta da idade avançada de Plínio Doyle.
} 
Assim, apesar de não ter trabalhos publicados nas áreas de História ou Geografia, Plínio Doyle ingressou no IHGB por conta de suas redes de sociabilidade. Amigo de longa data de nomes importantes dentro do Instituto, como Américo Jacobina Lacombe e Haroldo Valladão, Doyle foi eleito cinco anos depois do início das reuniões semanais em seu apartamento em Ipanema, época em que o evento já era famoso e atraía cada vez mais intelectuais. Além disso, o Sabadoyle parece também ter impulsionado a candidatura de outros frequentadores das reuniões, ao contribuir para a ampliação de suas redes de sociabilidade em interseção com intelectuais do Instituto.

Maria Diégues Quintella aponta justamente a ideia de "convivência intelectual" como um requisito informal, de caráter pessoal, mas extremamente importante para o ingresso nestas instituições culturais. Além disso, é comum e no entanto significativa a demonstração de um relacionamento pessoal existente entre esses intelectuais, referindo-se uns aos outros como "mestre", "conselheiro", "amigo pessoal”, etc, numa linguagem coloquial. (1984: 128)

Esse vocabulário mais informal, indicativo de uma relação de amizade, fazia parte dos rituais do Instituto e aparece com frequência nos discursos dos sócios. As expressões "amigo por inteiro", "companheiro", "confrade", "mestre", "queridos e velhos amigos" são algumas das denominações encontradas nas páginas da RIHGB. Esses termos indicam a existência de proximidade e afetividade entre os interlocutores e se configuram em elementos informais de admissão, coesão e delimitação do grupo. A autoidentificação entre os pares e o apontamento de relações internas de respeito e amizade ajudam a legitimar a coesão deste grupo de intelectuais e a marcar suas fronteiras em relação ao meio externo. (QUINTELLA, 1984: 122)

Além dos elogios trocados entre os próprios colegas de instituição, no entanto, os intelectuais do IHGB possuíam uma outra forte característica de autocultuação: o elogio direto e exacerbado à própria instituição. A começar pela forma como os sócios e demais convidados ilustres se referiam ao Instituto. Os apelidos eram inúmeros, sempre reverentes e elogiosos, e incluíam todos os tipos de combinações a partir de palavraschaves. A primeira palavra das expressões comumente adotadas remete à ideia de uma construção física, uma sede que abriga uma função nobre maior, e varia entre "casa", “academia", "silogeu”, “cenáculo", “catedral”, "mansão" e "templo”, seguida quase sempre da preposição “de". O segundo termo representa a função específica da instituição, aquilo que a diferencia das demais, revezando-se principalmente entre os termos "história", "cultura" e "memória". Por vezes adicionava-se ainda um 
complemento, como "pátria", "nacional", "brasileiro" ou "do Brasil", ou seja, majoritariamente relacionado ao patriotismo muito presente em toda a trajetória do Instituto.

Assim, ao longo dos 21 anos de edições da $R I H G B$ pesquisados, encontramos muitas denominações, tais como: "Templo da História Pátria"; "Casa da Memória Nacional", "Catedral da História do Brasil", "Silogeu brasileiro", “Academia de História", "Casa da Memória", "Casa da cultura nacional”, "Mansão da História e da Geografia do Brasil”, “Academia de História Pátria”, “Casa de cultura”, “Cenáculo de cultura histórica", "Casa da Memória do Brasil", "Academia da Memória e da Tradição", "Casa do Brasil”, entre muitos outros.

A partir dessas denominações já é possível começar a identificar que tipo de imagem, ou imagens, o IHGB procurava construir sobre si: o de quem abriga e é o responsável pela história e pela cultura brasileira, o de construtor e guardião do passado e da memória nacional, e em alguns momentos considerando-se inclusive um local sagrado, como se percebe através dos termos "catedral" e "templo".

Em novembro de 1964, o professor e jornalista cearense Francisco Mozart Rego Monteiro, sócio do Instituto desde 1949, publicou em O Jornal o artigo "O Templo da História Pátria está em perigo", transcrito no ano seguinte pela RIHGB. Mozart Monteiro denunciava as condições precárias da sede do Instituto à época, o Silogeu, e clamava pelas autoridades para auxiliar nas suas dificuldades financeiras e na construção da nova sede. Para convencer seus leitores, descreve o IHGB da seguinte forma:

O Instituto Histórico e Geográfico Brasileiro é uma entidade cultural que honra o Brasil. Talvez não haja outra no domínio da cultura com tantas tradições e tantos serviços relevantes prestados a este País. Fundado em 1838, conta hoje 126 anos sem solução de continuidade, tendo atravessado o fim da Regência, todo o $2^{\circ}$ Reinado e todas estas fases em que se vem desdobrando a República, desde 1889 até agora. É uma longa e gloriosa existência, sem paralelo na vida intelectual do Brasil. (RIHGB, jan./mar. 1965: 152)

Na posição de sócio do Instituto e jornalista dos Diários Associados, Mozart Monteiro destaca a longevidade do IHGB. Para isso, é evidenciado quando foi fundado 
e há quanto tempo perdura, atravessando as diferentes fases da história do Brasil. Essa aproximação entre as trajetórias do Instituto e do país é um recurso frequente desta autocultuação e tem a finalidade tanto de demonstrar a longevidade, a tradição e a constância do IHGB quanto de apresentar todos os serviços que já teriam sido prestados em favor do Brasil.

Em junho de 1970, na ocasião da posse do general Emílio Garrastazu Médici como presidente de honra do IHGB, Pedro Calmon saudou com um discurso elogioso o novo presidente militar, sem deixar de também saudar e reverenciar o próprio Instituto:

Criado em plena Regência para conservar a Memória da pátria, o Instituto juntou-lhe a ressonância cívica, porque à investigação da verdade - seu primeiro mandamento - acrescentou os entusiasmos comemorativos - sua obrigação pedagógica. Longe fulguravam os exemplos de heroísmo. Aqui recebiam-se os heróis. O que de efêmero tinha o fato grandioso, os historiadores supriram com a perpetuidade. É com razão transcendente que se tomou por costume recitar as Efemérides do barão do Rio Branco ao início dos trabalhos. Corresponde à liturgia dessas tertúlias serenas. Não recorremos ao acontecimento do dia. Voltamos aos dias santificados pela bravura ou pela ilustração, em que se distribui o calendário patriótico; refutamos o ingrato esquecimento; a nossa tarefa é reivindicatória; restituímos às novas gerações o que de imperecível houve nas gerações extintas; asseguramos o seu acesso à experiência; atualizamos o passado, não para que retarde, mas para que inspire; pelos modelos (imortais) plasmamos a imagem (nacional). (RIHGB, jul./set. 1970: 313)

É interessante observarmos os verbos escolhidos por Calmon para descrever as ações do Instituto: “conservar", “suprir”, “distribuir", "restituir", “assegurar", “atualizar”, “inspirar”, “plasmar”. Geralmente utilizados na primeira pessoa do plural, esses verbos demonstram a busca pela construção de uma imagem para o IHGB baseada na ideia de guarda, de conservação, de vigilância sobre o passado, pelo qual o Instituto seria responsável. Desta forma, Calmon destaca a importância do Instituto como o conservador da memória nacional. Suas funções principais seriam a investigação da verdade histórica e a obrigação pedagógica de transmitir esta verdade ao resto da sociedade brasileira. 
Os relatórios anuais, reunindo as informações mais relevantes do respectivo período e publicados na última edição de cada ano, também eram uma importante fonte de autocultuação do Instituto e cumpriam a função de apresentar e exaltar todas as atividades culturais realizadas. O relatório de 1964, apresentado pelo $1^{\circ}$ secretário à época, Virgílio Corrêa Filho, foi encerrado com as seguintes palavras: "Sumariadas destarte, as ocorrências, de que participou o Instituto Histórico durante o exercício, [...] comprovam que se esforça a centenária entidade por contribuir para o engrandecimento cultural, no âmbito das investigações, que lhe competem, como guardião vigilante das mais sadias tradições do Brasil” (RIHGB, out./dez. 1964: 276).

O uso da expressão "centenária entidade" indica novamente a intenção de destacar a longevidade da instituição, e, consequentemente, a sua constância e perpetuidade. Além disso, também se repete a ideia de "guarda" e de "vigilância", papéis atribuídos ao Instituto por conta de sua contribuição para o "engrandecimento cultural" do país.

Essa autocultuação é encontrada em todos os eventos realizados durante o ano social do Instituto, incluindo as sessões ordinárias e magnas. Aliás, a própria sessão magna anual, realizada em comemoração ao aniversário do IHGB, já se constitui, por si só, como uma forma de autocultuação da instituição. Prevista nos estatutos, a sessão especial frequentemente contava com a presença de membros do governo federal e estadual, além de demais políticos e intelectuais convidados, que iam prestigiar o aniversário do Instituto. Durante o período pesquisado, normalmente as sessões magnas incluíam a leitura das efemérides brasileiras do dia 21 de outubro, algumas palavras do presidente do IHGB e o elogio aos sócios falecidos.

Tradição do Instituto, os elogios consistiam em homenagem prestada após a morte dos intelectuais que passavam pela instituição e poderia acontecer de três formas distintas, embora com características em comum: na seção "Sócios Falecidos" da Revista, onde o Instituto comunicava o falecimento dos seus sócios na edição imediatamente seguinte, publicando um breve necrológio do intelectual; na sessão magna anual, em comemoração ao aniversário da instituição, quando o orador oficial fazia um discurso homenageando todos os sócios falecidos no respectivo ano social; e a realização de homenagens especiais, reservadas apenas a membros de grande importância para a história do IHGB, com a organização de uma conferência específica onde vários sócios proferiam exposições sobre diferentes aspectos da vida do sócio falecido. 
$\mathrm{Na}$ maior parte das vezes, os necrológios recontam a biografia do sócio homenageado, destacando suas principais obras, cargos públicos e outras instituições culturais de prestígio das quais tenha participado. Era também comum que fosse avaliada a participação do sócio falecido no IHGB, recontando quando e como acontecera sua eleição, por vezes até quais sócios propuseram seu nome e o parecer dado pela respectiva comissão; se o intelectual costumava frequentar ou não o Instituto; se publicou artigos na Revista ou participou de comissões especiais e permanentes enfim, analisava-se que tipo de contribuição o sócio falecido havia deixado de legado.

O próprio fato de o elogio aos sócios falecidos ser realizado, segundo exigem os estatutos, na sessão magna em comemoração ao aniversário do Instituto já é uma demonstração da importância simbólica deste ritual. O elogio aos falecidos, mais do que um necrológio, é um tributo ao próprio IHGB e uma forma de celebrá-lo. A comemoração do aniversário do Instituto e o elogio aos mortos eram praticamente um ritual só, interligados em todas as sessões magnas anuais e considerados partes da mesma tradição. E esse aspecto está presente em todos os discursos, independentemente de quem era o orador oficial.

Quando Haroldo Valladão assumiu a tribuna, já na década de 1970, seus discursos traziam constantemente esse aspecto de louvor ao Instituto. No ano de 1973, por exemplo, o orador faz o elogio aos sócios falecidos de forma poética, homenageando não só os intelectuais que se foram, mas principalmente o IHGB:

Unidos, mais uma vez, em belíssima tradição das instituições culturais pátrias, a sua glória à dos seus membros falecidos, acoplando o seu apogeu à exaltação da vida dos confrades que partiram, unindo o seu triunfo à sua saudade, reverencia hoje o Instituto a memória dos que nos deixaram, no último ano estatutário, de 21 de outubro de 1972. [...] Examinando a vida dos seis confrades que perdemos, temos uma amostra do importante valor de nosso Instituto, pelo muito que realizaram, cada qual na sua especialidade profissional e cultural, mas todos, excelentemente e com a mesma fé, em prol da historiografia e da geografia, a bem de nossas supremas finalidades, no amor da pátria e das letras. (RIHGB, out./dez. 1973: 131)

Além do patriotismo, que aparece aqui como unificador tanto das instituições culturais quanto dos sócios do IHGB, percebemos também como andam lado a lado as "glórias" do Instituto e de seus sócios falecidos, onde o triunfo e o apogeu de um estão 
diretamente ligados à saudade e à exaltação do outro. Valladão afirma de forma direta, nesta passagem, como as homenagens aos intelectuais que se foram e a exaltação as suas histórias de vida são, no fim das contas, uma exaltação ao próprio IHGB, pois essas trajetórias fornecem "uma amostra do importante valor de nosso Instituto, pelo muito que realizaram".

No ano anterior, em 1972, Américo Jacobina Lacombe foi o responsável pelo elogio aos sócios falecidos. Após prestar homenagem a todos os intelectuais que se foram naquele ano, Lacombe dirige-se diretamente aos sócios presentes na sessão magna e profere as seguintes palavras de otimismo:

Meus senhores,

Esta oração de saudade não deve terminar nunca sem um brado de esperança. A continuidade das monarquias exprimia-se por um grito chocante e célebre: Le roi est mort, vive le roi. Foram-se alguns companheiros de trabalho, que nos deixaram atônitos pela rapidez do desaparecimento. Mas as cadeiras estão preenchidas. Os esforços que eles despenderam não serão perdidos na continuidade da obra coletiva que por mais de um século vimos mantendo e que, um dia sem nós, sem todos os que aqui estamos, prosseguirá por séculos afora enquanto houver Brasil. Tal é a glória das grandes instituições culturais. (RIHGB, out./dez. 1972: 294)

O encerramento do discurso de Lacombe é um elogio à perenidade e à imortalidade do IHGB, argumentando que os sócios falecidos e os presentes são, na verdade, parte de um todo maior, de permanência infindável. Estes sentimentos de constância e de perpetuidade são os que revelam a "glória" das grandes instituições culturais, como o IHGB, e as transformam no meio pelo qual esses intelectuais conseguem atingir a consagração eterna. A mensagem passada, por tanto, é de homenagem aos falecidos, mas, principalmente à Casa que os abriga e que dá sentido as suas existências como intelectuais.

\section{Considerações finais}

As possibilidades e os lugares onde a autocultuação acontecem são inúmeros e certamente inspirariam ainda muitos outros artigos. Procurou-se aqui apresentar o 
assunto de forma introdutória, pensando em qual imagem os sócios do IHGB procuravam construir para a instituição e para si mesmos. A partir dos discursos, relatórios, conferências e artigos encontrados, destaca-se a tentativa de o Instituto se mostrar mesmo como uma entidade, responsável pela formação da nação brasileira a partir da construção do passado, e portanto imprescindível para a constituição do país. Verifica-se ainda a relação direta do IHGB com ideias de longevidade, tradição, guarda e vigilância.

Além do elogio direto ao Instituto, pôde-se perceber como a autocultuação é feita entre os próprios intelectuais, com trocas de elogios, homenagens, discursos de saudação, reverência aos sócios falecidos, etc. Afinal, elogiar e engrandecer a instituição da qual se fazia parte, assim como os demais intelectuais que a integravam, era também uma forma de se valorizar, enaltecendo seu próprio feito de pertencer àquele espaço.

Para Maria Diégues Quintella, apesar de esta autocultuação acontecer através de mecanismos distintos, referindo-se tanto a pessoas quanto à instituição, ela visa à legitimação deste grupo seleto de intelectuais: "estas instituições tendem a reverenciar o passado como uma forma de explicar e legitimar não apenas a ação presente mas também a própria posição ocupada por seus membros neste universo cultural" ${ }^{\prime 5}$.

Os diversos tipos de discursos e rituais presentes no cotidiano do IHGB analisados ao longo deste artigo, portanto, evidenciam não somente as práticas intelectuais próprias deste tipo de instituição cultural, mas também as características que tornam este grupo homogêneo e coeso - não necessariamente sem disputas internas, mas sim mediando essas disputas de modo que não ponham em risco a sua posição de poder.

\section{Fontes}

Instituto Histórico e Geográfico Brasileiro (IHGB) - Arquivo IHGB; Coleção RIHGB.

\section{Referências bibliográficas}

ABREU, Alzira Alves de; BELOCH, Israel; LAMARÃO, Sérgio \& LATTMANWELTMAN, Fernando (Orgs.) (2001). Dicionário histórico-geográfico brasileiro. 1930-2000. Rio de Janeiro: Editora FGV.

\footnotetext{
${ }^{5}$ QUINTELLA, Maria Diégues. Op Cit., p. 133.
} 
ABREU, Regina (1994). Entre a nação e a alma: quando os mortos são comemorados. Estudos Históricos. Rio de Janeiro, CPDOC, v. 7, n. 14, p. 206-230.

CALABRE, Lia (2006). Intelectuais e política cultural: o Conselho Federal de Cultura. Intellèctus. Rio de Janeiro, v. 2, n. 5, 17-18 mai. Disponível em: <http://www.casaruibarbosa.gov.br/dados/DOC/artigos/aj/FCRB_LiaCalabre_Inte lectuais_e_PoliticaCultural.pdf $>$. Acesso em: 13 jul. 2019. (2006). O Conselho Federal de Cultura, 1971-1974. Estudos Históricos. Rio de Janeiro, CPDOC, n. 37, p. 81-98, jan./jun.

CUNHA, Diogo (2014). Les intellectuels conservateurs entre le culturel et le politique : L'Académie Brésilienne des Lettres pendant la dictature militaire (1964-1979)". Tese (Doutorado em História) - Université Paris I, Paris.

GOMES, Angela de Castro (2009). A República, a história e o IHGB. Belo Horizonte: Argvmentvm.

\& HANSEN, Patricia Santos (Orgs.) (2016). Intelectuais mediadores: práticas culturais e ação política. Rio de Janeiro: Civilização Brasileira.

\& SCHMIDT, Benito Bisso (Orgs.) (2009). Memórias e narrativas (auto)biográficas. Porto Alegre/Rio de Janeiro: Ed UFRGS/Ed FGV.

GONTIJO, Rebeca (2005). História, cultura, política e sociabilidade intelectual. In: SOIHET, Rachel; BICALHO; Maria Fernanda Baptista \& GOUVÊA, Maria de Fátima Silva (Orgs.). Cultura políticas: ensaios de história cultural, história política e ensino de história. Rio de Janeiro: Mauad.

GUIMARÃES, Lucia Maria Paschoal (2007). Da Escola Palatina ao Silogeu: Instituto Histórico e Geográfico Brasileiro (1889-1938). Rio de Janeiro: Museu da República.

(1995). Debaixo da imediata proteção de Sua Majestade Imperial. O Instituto Histórico e Geográfico Brasileiro (1838-1889). RIHGB. Rio de Janeiro, n. 388, jul./set.

GUIMARÃES, Manoel Luiz Lima Salgado (Org.) (2007). Estudos sobre a escrita da história. Rio de Janeiro: 7Letras.

(1988). Nação e civilização nos trópicos: o Instituto Histórico e Geográfico Brasileiro e o projeto de uma história nacional. Estudos Históricos. Rio de Janeiro, CPDOC, n.1, p. 5-27.

INSTITUTO HISTÓRICO DE PETRÓPOLIS (s.d.) Disponível em: <http://ihp.org.br/26072015/site/default.htm>. Acesso em: 30 jul. de 2019.

INSTITUTO HISTÓRICO E GEOGRÁFICO BRASILEIRO (1991). Dicionário Bibliográfico de Historiadores, Geógrafos e Antropólogos Brasileiros. Rio de Janeiro: Instituto, v. 1.

INSTITUTO HISTÓRICO E GEOGRÁFICO BRASILEIRO (1992). Dicionário Bibliográfico de Historiadores, Geógrafos e Antropólogos Brasileiros. Rio de Janeiro: Instituto, v. 2.

LEVILLAIN, Philippe (2003). Os protagonistas da biografia. In: RÉMOND, Réne (Org.). Por uma história política. Rio de Janeiro: Ed FGV, p. 99-140.

LORIGA, Sabina (2012). O pequeno X: da biografia à História. Belo Horizonte: Autêntica.

MAIA, Tatyana de Amaral (2012). Os cardeais da política nacional: o Conselho Federal de Cultura na ditadura civil-militar (1967-1975). São Paulo: Itaú Cultural: Iluminuras.

QUINTELLA, Maria Madalena Diegues (1984). Cultura e poder ou espelho, espelho meu: existe alguém mais culto do que eu?. In: MICELI, Sérgio (Org.). Estado e cultura no Brasil. São Paulo: Difel. 
RANGEL, Rosângela Florido (2008). SABADOYLE: uma academia literária alternativa? Dissertação (Mestrado em Bens Culturais e Projetos Sociais) - Centro de Pesquisa e Documentação de História Contemporânea do Brasil (CPDOC), Rio de Janeiro.

SIRINELLI, Jean-François (1998). "As elites culturais". In: RIOUX, Jean-Pierre \& SIRINELLI, Jean-François (Orgs.). Para uma história cultural. Lisboa: Editorial Estampa.

(1996). Os intelectuais. In: RÉMOND, René (Org.). Por uma História política. Rio de Janeiro: FGV.

Artigo recebido em 21 de agosto de 2019.

Aprovado em 14 de fevereiro de 2020.

DOI: $10.12957 /$ intellectus.2020.44717 